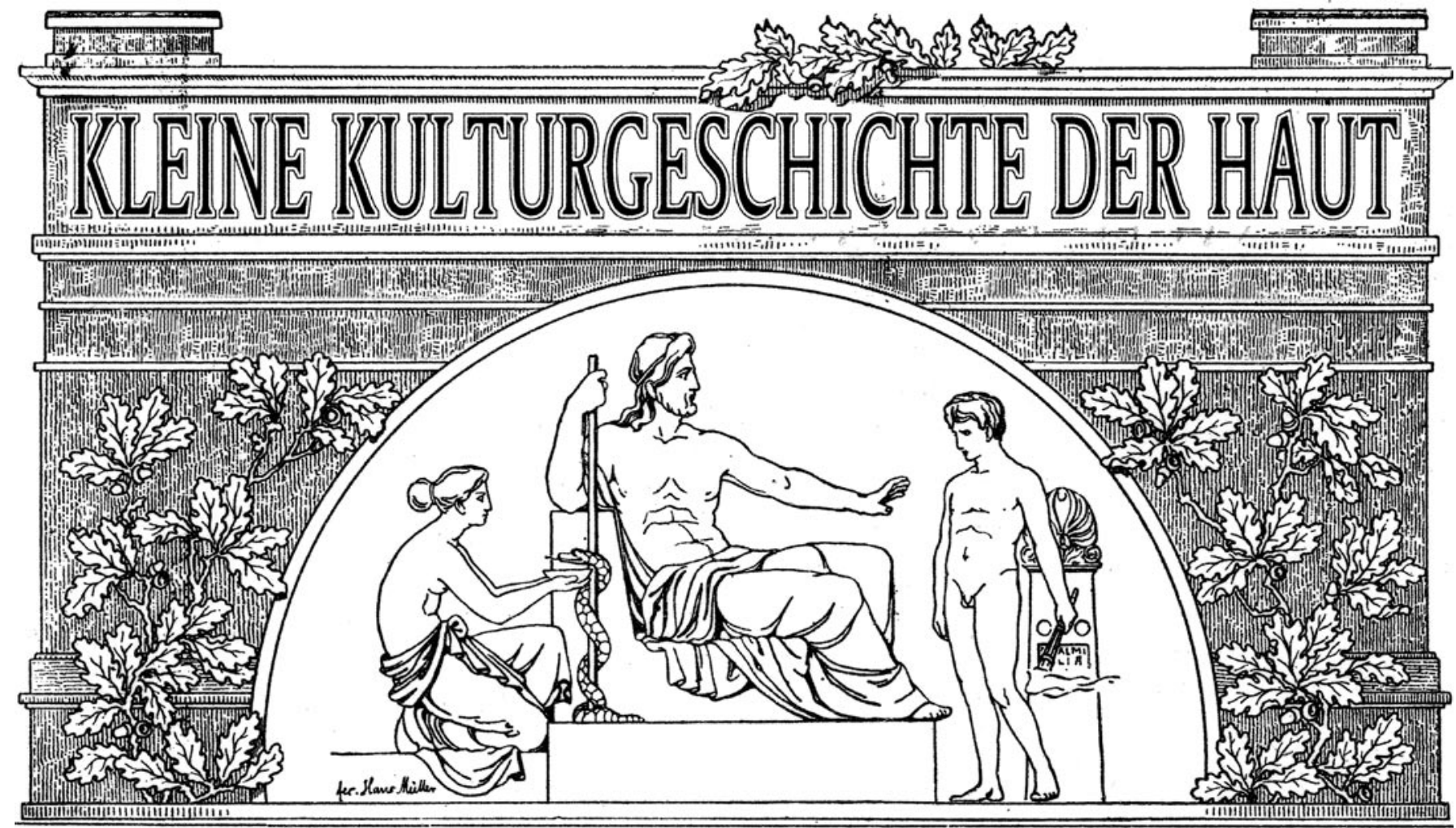

Die Zeitschrift „Aktuelle Dermatologie“ öffnet diese Rubrik und wird in loser Folge kurze, prägnante und informative Artikel darbringen zu vielen Aspekten der Kulturgeschichte in Beziehung zur Haut. Dies erstreckt sich auf alle Kulturen und Zeiten, auf die Künste, auf Mythen und Psychologie sowie natürlich auch auf medizinische Aspekte. Wir hoffen, dem geneigten Leser dadurch Interesse zu wecken, den Blick $z u$ weiten und Freude zu bereiten. Wir wünschen dieser Rubrik eine gute Aufnahme bei unseren Lesern und sind dankbar für Ihre Kommentare und Vorschläge für eine kleine Kulturgeschichte der Haut.

\title{
Fit forever mit Haut und Haaren
}

\section{G. Frank}

Auch auf unsere gute alte Haut ist die aktuelle Fitness-WellnessWelle übergeschwappt. Straff und jung soll sie sein, ergo der Kampf gegen Fettpolster und Falten ist eröffnet. So ausufernd wie die Liste der vermeintlichen Ursachen von Cellulite und anderen Makeln der schönen fitten Welt, liest sich auch die Litanei der angeblichen Erfolgstherapien: Massagen mit Bürsten, Rollern oder Vibratoren, Vakuumpumpen, Bodywrapping à la holländische Salatgurke und natürlich Cremes, Lotionen sowie Badezusätze, die die abgelagerten Schlacken auflösen sollen (im Körper und nicht in der Badewanne). Natürlich nicht zu vergessen die „rein pflanzlichen“ Kapseln und Pillen mit den „lebenswichtigen Vitaminen und Mineralstoffen“, die die Fettverbrennung anregen, freie Radikale abfangen, den Stoffwechsel ankurbeln oder sonstige medizinische Wunder vollbringen, die bis dato dem Weihwasser vorbehalten waren.

Schaut man einmal hinter die Kulissen der wunderbaren Versprechungen, sieht es dann doch eher mau aus. Generell wird in der
Fachliteratur beklagt, dass z. B. bis heute „noch keine effektive Behandlung oder Verhütung der Cellulite nachgewiesen wurde“ und dass „nur wenig wissenschaftliche Evidenz existiert, um auch nur eine der vielen beworbenen Behandlungsmethoden zu unterstützen“. Wenn es schon nicht wirkt - so schadet es doch wenigstens nicht? Irrtum, sagen Dermatologen, wenn sie an Anti-CelluliteCremes denken. Finnische Wissenschaftler hatten 32 Produkte unter die Lupe genommen. Insgesamt waren 263 verschiedene chemische Substanzen darin enthalten. Sie fanden allein 44 verschiedene pflanzliche Inhaltsstoffe, 39 verschiedene „Emolletien“ und natürlich allerlei Konservierungsstoffe und Duftstoffe. Ein Viertel der gefundenen Zutaten war als allergen bekannt, in vielen Fällen aber nicht in geeigneter Weise deklariert.

Eine englische Forschergruppe wandte sich gezielt einer so genannten Aminophyllin-Creme zu, die das Cellulite-Fett angeblich in Fettsäuren zerlegt. Wie erwartet zeigte das Produkt im Experiment ebenfalls keinen Effekt - außer Hautreizungen und allergische Reaktionen bei jeder vierten Versuchsperson. In einer anderen Studie aus Großbritannien wurde eine Kapsel, die Cellulite 
von innen heraus bekämpfen sollte, gegen ein Plazebo getestet. Selbst die vereinten Kräfte von Gingko, Süßklee, Grapefruitsamen, Blasentang, Nachtkerzenöl, Sojalecithin, Borretschsamenöl, Fischöl und anderen Leckereien brachten keinen Erfolg. Bedenklich stimmt jedoch der hohe Jodanteil des Präparates. Jede Kapsel enthielt $240 \mathrm{mg}$ des Mineralstoffes. Die Weltgesundheitsorganisation (WHO) empfiehlt nur $150 \mathrm{mg}$ Jod pro Tag aufzunehmen. Zu viel Jod kann Schilddrüsenstörungen hervorrufen. Von den Kapseln sollten die Frauen laut Hersteller aber gleich $2-3$ pro Tag einnehmen...

Bodywrapping - das Einpacken in Folie und Gummianzüge - vermag entgegen den Werbeversprechen prinzipiell kein „Fett abzuschmelzen“. Schließlich bestehen die Fettdepots nicht aus Butter, sondern aus Fettzellen. Das Verfahren presst lediglich etwas Lymphflüssigkeit, also Wasser, aus den Pobacken - etwa so, wie auch ein Saftschinken unter Druck etwas Wasser absondert. Ebenfalls nicht empfehlenswert ist nach Auffassung von Alexander Konstantinow, Dermatologe an der Universitäts-Hautklinik München, die so genannte Cellulipolyse. Dabei soll - so die eigenwillige Theorie - der Stoffwechsel der Fettzellen mit Hilfe von Gleichstrom angeregt werden. „Wissenschaftlich haltbare Studien sind nicht bekannt“, so Konstantinow. „Das Verfahren ist teuer, zeitaufwändig und schmerzhaft.“

Auch die Stiftung Warentest nahm sich jüngst des klebrigen Themas an. Fazit der Tester: „es hat nicht gewirkt (...) weder Creme, Gel, Serum oder Spray noch das Massagegerät haben einen positiven Einfluss auf die welligen Pölsterchen. Nach wie vor gilt: schlanker wird nur das Portemonnaie." Die einzige wirksame Methode, um das Fett zurückzudrängen, besteht deshalb weder in Cremetöpfchen noch in Massageapparaten, sondern ausschließlich im Kampf gegen das Unterhautfettgewebe, verkünden einige Experten. Und sie wissen auch schon wie: mit fettarmer, ballaststoffreicher Diät und viel Sport, „am besten Joggen“. Warum? Weil das „in den betroffenen Hauptpartien Muskeln aufbaut“ orakelt Gisela Albrecht, Direktorin der Klinik für Dermatologie und Allerlogie am Klinikum Berlin-Spandau, in der Zeitschrift test.

Also raus aus dem Bodywrapping, weg mit den Cremes und rein in die Joggingschuhe. Schön wär's, leider sind die versprochenen positiven Wirkungen der täglichen Ertüchtigung durchaus wissenschaftlich umstritten. Weder kann durch zusätzlichen Sport eine nachhaltige Gewichtsverringerung erzielt werden, und auch die Kombination mit einer Diät bringt im Vergleich zur Nur-DiätGruppe keinen weiteren Gewichtsverlust. Zum Trost für die Jogger sei allerdings hier nicht verschwiegen, dass alle Diäten nach spätestens 2 Jahren wieder zum Ausgangsgewicht zurückführen und als Sahnehäubchen zum Andenken noch mit ein paar Extrakilos dazu.

Joggen eignet sich dagegen, insbesondere für schlanke Frauen, ganz besonders gut als Einstiegsdroge in die athletische Triade mit Essstörung, Osteoporose und Menstruationsstörungen. Auch besonders sensible Stellen der Haut, unsere Brustwarzen entzünden sich nicht selten, wenn sie im Laufrhythmus an der Kleidung scheuern. In der Fachliteratur als „Joggernippel“ bekannt, empfehlen Fachleute deshalb einen passenden BH oder das Überkleben bzw. regelmäßige Fetten der Warzen. Übrigens kein rein weibliches Problem.
Zu besonderer Zurückhaltung rät Janet T. Wallis von der Universität Bloomington stillenden Joggerinnen. Sie erkannte, dass man nicht gleich an eine gestörte Mutter-Kind-Beziehung denken sollte, wenn Säuglinge sich weigern, an der Brust ihrer sportlichen Mama zu nuckeln. Vielleicht ist ja nur die Milch sauer. Bekanntlich steigt bei körperlicher Aktivität die Laktat- sprich die Milchsäurekonzentration im Blut und damit natürlich auch im Brustsekret. Wallis' Messungen ergaben, dass bereits mäßiges Joggen das Laktat so stark ansteigen lässt, dass so manche Muttermilchprobe von erwachsenen Testpersonen als sauer empfunden wird. Folge des mütterlichen Bewegungsdrangs: Die Säuglinge treten in den Hungerstreik. Wer trinkt schon gern verdorbene Milch?

Da nun auch bei der Radikallösung des Fettpölsterchenproblems, der Fettabsaugung, die Erfolge durchaus geteilt gesehen werden können - die abgesaugten Fettmengen wachsen nämlich nach einiger Zeit wieder nach, nur weiß man nicht an welchen Stellen! -, scheint die einzige Lösung die gesunde Ernährung zu sein, um das Ziel jugendliche Haut und straffer Hintern zu erreichen. Doch leider ist das Konzept einer allgemeingesunden Ernährung so plausibel wie eine allgemeingesunde Schuhgröße, so groß ist unsere genetisch bedingte Streuung unterschiedlicher Verdauungsenzyme. Auch die vielgerühmte ballaststoffreiche Ernährung bringt durch Überlastung der Darmflora letztlich keinen anderen Erfolg als Blähungen mit viel heißer Luft.

Alles ziemlich schwer verdaulich für die Gemeindemitglieder der Forever-young-Community. Glauben sie doch inbrünstig, alles sei nur eine Frage des disziplinierten Lebensstils, weshalb sie gerne herabschauen auf Menschen, die mit dem bewährten Standardmodell herumspazieren und sich dabei noch gut fühlen. Übertrieben? Immerhin $42 \%$ unter den Dreißigjährigen stimmen z. B. dem Satz zu: „Wer nicht an sich arbeitet, um eine gute Figur zu haben und leistungsfähig zu bleiben, ist selbst schuld, wenn er z. B. berufliche Nachteile hat oder nicht so leicht einen Partner findet.“ Das ermittelte das Institut für Demoskopie Allensbach im Auftrag der Körperstiftung im Oktober 2000.

Was also tun? Am besten wir hören anstatt auf diverse „Experten“ in Funk und Fernsehen lieber wieder mehr auf die eigentlichen Bedürfnisse unseres eigenen Körpers, die er uns ganz individuell in Form von Instinkten wie Appetit oder auch Befindlichkeit mitteilt. Er hat ein Recht darauf, schließlich trägt er uns durch dick und dünn und darf dabei die eine oder andere Schramme abbekommen. Tragen wir im Alter unsere schrumpelige Haut als Zeichen der Würde und der Bewältigung eines ereignisreichen Lebens. Seien wir ruhig stolz auf sie. Eine andere Wahl scheinen wir eh nicht zu haben.

\section{Literatur}

${ }^{1}$ Pollmer U, Warmuth S, Frank G. Lexikon der Fitnessirrtümer. Eichborn, 2003

Dr. med. Gunter Frank

Schlossberg 2, 69117 Heidelberg, E.mail: frank@spraxis.de 